\title{
Possibility of Alveolar Bone Promoting Enhancement by Using Lipophilic and/or Hydrophilic Zinc Related Compounds in Zinc-Deficient Osteoporosis Rats
}

\author{
Yoshihiro Tokudome ${ }^{\dagger}$ and Makoto Otsuka* \\ Research Institute of Pharmaceutical Sciences, Musashino University; 1-1-20 Shinmachi, Nishi-Tokyo, Tokyo 202- \\ 8585, Japan. Received March 1, 2012; accepted June 18, 2012
}

The purpose of this research is improvement of therapeutic treatment for periodontitis by using lipophilic and/or hydrophilic zinc materials. The sample suspension injections were prepared from zinc octanate $(\mathrm{C8Zn})$, zinc stearate $(\mathrm{C18Zn})$, zinc sulfate hepta-hydrate $\left(\mathrm{ZnSO}_{4}\right)$ and tricalcium phosphate $(\mathrm{ZnTCP})$ containing 6.17w/w\% zinc. After administrating of all injections to around alveolar bone of zinc-deficient osteoporosis rats, plasma $\mathrm{Zn}$ concentration, bone mineral content (BMC) of jawbone, BMC and bone mechanical strength (BMS) of femur and permeability tests for hairless rat stripped skin were measured as therapeutic scores. BMC and BMS were measured by using an X-ray computing tomography and the three-point bending method, respectively. The body weight, plasma $\mathrm{Zn}$ concentrations and the area under curve (AUC) for $\mathrm{Zn}$ of $\mathrm{C8Zn}, \mathrm{C18Zn}$ and $\mathrm{ZnTCP}$ group rats were higher than those of control group, but those of $\mathrm{ZnSO}_{4}$ group were not changed. BMC of alveolar bone and femur and BMS of femur for C8Zn and C18Zn groups for 12 weeks were significantly higher than those of the control group, but those of $\mathrm{ZnSO}_{4}$ group were not changed. Stripped rat skin permeability treated by the hydrophilic creams containing C8Zn was 5-times higher than that of ZnTCP.

Key words suspension injection; zinc octanate; zinc stearate; alveolar bone mineral content; bone mechanical strength; plasma zinc concentration

Periodontal disease begins with inflammation cause of bacteria buildup surrounding teeth. When it is deteriorated, the toxin from bacteria stimulates abnormally the osteoclast which plays a role in bone resorption, the alveolar bone supporting teeth begins to dissolve, and teeth may be dropped. Thus, as the lifestyle habit and the relation of many diseases become clearer, the concepts of primary prophylaxis is becoming more important that we need to establish healthy lifestyle and prevents onset of periodontal disease. Additionally, it becomes increasingly clear that treatment of periodontal disease is not only to treat periodontium but also to improve and prevent of onset and progression of systemic disease.

The most important clinical point for periodontal diseases is resorption of the alveolus bone. The mechanism for destruction of the same bone osteoclast participates between alveolar bone retraction in periodontal disease and bone destruction in osteoporosis. ${ }^{1,2}$ Recently, the treatment for the alveolus bone loss due to periodontal disease is the most necessary treatment. In general, it is thought that plaque microorganism and product material are the leading causes of periodontosis. However, the medical treatment by the antibiotic and an antiinflammatory agent is only to inhibit partially the progression of periodontitis. Therefore, a treatment by antibiotics, astringent, and gargle is not effective over a long period of time. About bone density, it is known that there are close relations between the bone density of whole teeth, particularly femoral bone density and periodontal condition.

Zinc ( $\mathrm{Zn})$, an essential element and a cofactor for more than 200 enzymes, is present in nearly every type of cell in the body. $\mathrm{Zn}$ is important for cell proliferation, immunity, spermatogenesis, wound healing, and maintaining the senses of taste

The authors declare no conflict of interest.

${ }^{\dagger}$ Present address: Faculty of Pharmaceutical Sciences, Josai University; 1-1 Keyakidai, Sakado, Saitama 350-0295, Japan. and smell. It also has a very important role in the formation of bone. In fact, the concentration of $\mathrm{Zn}$ in bone is higher than that in any other tissue. Zn promotes protein synthesis, and the proliferation and differentiation of osteoblasts. However, as $\mathrm{Zn}$ is an important essential metal with very strong bioactivity, and has serious side effects at high concentrations in blood, ${ }^{3)}$ controlling its release is vital for therapeutic use. Recently, a clinical relationship between osteoporosis and Zn deficiency has been established in elderly subjects. ${ }^{4,5}$ In addition, the utility of the $\mathrm{Zn}$ as the essential trace metal has been reviewed. ${ }^{6}$ Bone-promoting effects of $\mathrm{Zn}$-containing $\beta$-tricalcium phosphate ceramics have been reported. ${ }^{7)}$ Stimulatory effects on osteogenesis of injections of $\mathrm{Zn}$-containing calcium phosphate suspension were also reported. ${ }^{8)}$ Bone was stimulated to form around $\mathrm{Zn}$-containing calcium phosphate ceramics implanted in rabbit femora. ${ }^{9}$ Using an animal model of osteoporosis, it was found that the injection of $\mathrm{Zn}$-containing tricalcium phosphate (ZnTCP) was effective in recovering bone mineral density. ${ }^{10)}$ Particularly, the Zn-containing $\beta$-tricalcium phosphate nano particles were administered by injection around alveolar bone and effective at preventing bone loss induced by ovariectomy in rats and have potential uses for treating periodontitis. ${ }^{11)}$ We also have developed the validity of ZnTCP and other zinc related compounds in order to control $\mathrm{Zn}$-release for improvement of various pharmacological effectiveness of $\mathrm{Zn}$ using different dosage forms. However, the $\mathrm{Zn}$ could not be absorbed well from skin and oral mucosa, because $\mathrm{Zn}$ containing calcium phosphates are hydrophilic compounds. When the compounds are applied to improvement of alveolar bone mineral density, an injection or small surgical operation is required. However, the pain by the operations is difficult for the patients. Therefore, the patient friendly $\mathrm{Zn}$ administration such as a transdermal therapeutically system is required from the viewpoint of patient quality of life (QOL) as a final purpose. So, as a first step, it is inspected whether 
the candidate lipophilic $\mathrm{Zn}$ compounds are effective for new periodontitis treatment. In the present study, new $\mathrm{Zn}$ containing materials, such as $\mathrm{Zn}$ octanate, stearate and $\mathrm{Zn}$ sulfonate 7 hydrate, are used as candidate compounds for therapeutic treating periodontitis. Suspension injections of the compounds were administrated for around alveolar bone of $\mathrm{Zn}$-deficient osteoporosis rats, and measured plasma $\mathrm{Zn}$ levels, after then, evaluated bone mineral content of alveolar bone, bone mineral density of femur, bone mechanical strength of femur, as therapeutically score. Furthermore, in order to improve the QOL of the patients during therapeutic treatment, we considered that their dosage forms of candidate compounds changed to oral ointment to avoid injection into mouth. Permeability tests of candidate lipophilic $\mathrm{Zn}$ related compounds for hairless rat stripped skin were, therefore, performed as basic information to develop orally administrative ointments.

\section{MATERIALS AND METHODS}

Materials ZnTCP containing $10 \mathrm{~mol} \%$ zinc $(6.17 \mathrm{w} / \mathrm{w} \%$ zinc) $\left[\mathrm{Ca}_{2.7} \mathrm{Zn}_{0.3}\left(\mathrm{PO}_{4}\right)_{2}\right]$ was prepared as described elsewhere. ${ }^{12,13)}$ Zinc sulfonate 7 hydrate was obtained from Wako Pure Chemical Industries, Ltd. (Osaka, Japan), Zinc octanate $\left[\left(\mathrm{C}_{7} \mathrm{COO}\right)_{2} \mathrm{Zn}, \mathrm{C} 8 \mathrm{Zn}\right]$ and zinc stearate $\left[\left(\mathrm{C}_{17} \mathrm{COO}\right)_{2} \mathrm{Zn}, \mathrm{C} 18 \mathrm{Zn}\right]$ was purchase from Mitsuwa Chemicals Co., Ltd. (Osaka, Japan) and Wako Pure Chemical Industries, Ltd., respectively. Corn oil, purchased from Wako Pure Chemical Industries, Ltd., and sodium pentobarbital, from Dainippon Pharmaceutical Co., Ltd. (Osaka, Japan). Zn-test Wako was obtained from Wako Pure Chemical Industries, Ltd. Other reagents were of analytical grade and used without further purification.

Animal Experiments Four-week old female SpragueDawley (SD) rats (average body weight: 65-75g) purchased from Japan Clea Inc. (Tokyo, Japan) were used. The rats were maintained in a light- $(12 \mathrm{~h}$ light/dark) and temperature- $(25 \pm$ $2^{\circ} \mathrm{C}$ ) controlled barrier facility throughout the study. All animal experiments and maintenance were performed under conditions approved by the animal research committee of Musashino University. The rats were fed a diet deficient in vitamin D, Ca, and Zn (-DCaZn) for 1 week, and Zn-deficient rats with osteoporosis were prepared following the modified protocol reported by Yamaguchi et al. and Suda et al. ${ }^{14,15)}$ The rats were randomly assigned to five groups (six rats per group; control, and $\mathrm{ZnTCP}$ and $\mathrm{ZnSO}_{4}, \mathrm{C} 8 \mathrm{Zn}$ and $\mathrm{C} 18 \mathrm{Zn}$ ), and bilaterally ovariectomized 5 weeks before the start of injections (age at OVX, five weeks), and fed a normal diet for 1 week and the $-\mathrm{DCaZn}$ diet for 4 weeks. On commencement of the experiments, the groups of control, and $\mathrm{ZnTCP}$ and $\mathrm{ZnSO}_{4}$, $\mathrm{C} 8 \mathrm{Zn}$ and $\mathrm{C} 18 \mathrm{Zn}$ were intramuscularly injected suspension containing no-admiration, $\mathrm{ZnSO}_{4}, \mathrm{ZnTCP}, \mathrm{C} 8 \mathrm{Zn}$ and $\mathrm{C} 18 \mathrm{Zn}$ $(0.6 \mathrm{mg}$ as zinc) in $0.2 \mathrm{~mL}$ of corn oil on around the alveolar bone once a week for 12 weeks, respectively. The group of normal (six rats) did not under go an ovariectomy and received a normal diet throughout the experimental period. After blood samples were obtained at 0, 2, 4, 8, 24, 48 and $72 \mathrm{~h}$ from the tail artery of the rats, the samples were immediately centrifuged at $4660 \times \boldsymbol{g}, 5 \mathrm{~min}(\mathrm{CR} 13 \mathrm{R}$, Hitachi Koki Co., Ltd., Tokyo, Japan) and a each plasma sample was stored at $-30^{\circ} \mathrm{C}$.

Measurement of $\mathrm{Zn}$ Concentrations in Plasma Samples The concentration of $\mathrm{Zn}$ in plasma was determined based on the 5-Br-PAPS method, which uses the reagent 2-(5-bromo-2-pyridylazo)-5-( $N$ - $n$-propyl- $N$-3-sulfopropylamino)phenol (Zn-test Wako, Wako Pure Chemical Industries, Ltd., Tokyo, Japan). ${ }^{16)}$ The measurement was made using a UV/VIS spectrometer (Type UV4200, Shimadzu, Kyoto, Japan) at $560 \mathrm{~nm}$. The data represent the averages of 4 measurements each. Area under the concentration $v s$. time curve for $72 \mathrm{~h}\left(A U C_{0-72}\right)$ calculated using the trapezium method.

Diets for Rats A diet deficient in vitamin $\mathrm{D}$ and $\mathrm{Zn}$ $(-\mathrm{DZn})$ was used. The $-\mathrm{DCaZn}$ diet and normal diet were prepared and supplied by Clea Co., Ltd. (Tokyo, Japan). The -DZn diet was prepared by supplementing the $-\mathrm{DCaZn}$ diet with calcium carbonate at $1.5 \%$. The composition of all the diets was given in a previous paper. ${ }^{17)}$

X-Ray Computed Tomography (CT) Analysis The rats were anesthetized with an intraperitoneal (i.p.) injection of sodium pentobarbital $(50 \mathrm{mg} / \mathrm{kg})$ before each treatment. Bone mineral content (BMC) was also measured using an X-ray CT for animals scanner (LCT-100A, ALOKA, Tokyo, Japan) once a week under anesthesia (conditions of X-ray CT; pixel size; $480 \times 480$, fan beam; tube voltage; $50 \mathrm{kV}$, tube current; $1 \mathrm{~mA}$, resolution; $0.25 \mathrm{~mm}$ ).

Bone Mechanical Strength (BMS) After 12 weeks, all the rats were sacrificed with an overdose of sodium pentobarbital. The three-point bending strength of excised right and left femurs was measured as described with a bending speed of $0.164 \mathrm{~mm} / \mathrm{s}$ using a type $50 \mathrm{kN}$ (Minebea, Kanagawa, Japan). ${ }^{18)}$ Maximum bending force (N) was used as an index of bone mechanical strength (BMS).

Skin Permeation Study Abdominal full-thickness skin of hairless rats (HWY stain, 7-weeks-old, male) was excised under anesthesia by i.p. injection of sodium pentobarbital $(50 \mathrm{mg} / \mathrm{kg})$. Excised skin and stratum corneum stripped skin which excess subcutaneous fat was carefully eliminated was mounted in a modified Franz-type diffusion cell having an effective diffusion area of $1.13 \mathrm{~cm}^{2}$. To obtain stratum corneum (SC)-stripped skin, adhesive tape was applied to hairless mouse skin with uniform pressure and then removed. This procedure was repeated 20 times. The receiver solution was $6.0 \mathrm{~mL}$ of acetate-buffered solution, $\mathrm{pH} 4.0$, which was maintained at $32^{\circ} \mathrm{C}$. The donor compartment contained Zn-TCP, $\mathrm{ZnSO}_{4}, \mathrm{C} 8 \mathrm{Zn}$ and $\mathrm{C} 18 \mathrm{Zn}$ in acetate buffer as $3000 \mu \mathrm{g}$ zinc. The skin permeation of zinc concentration was determined in all samples by Inductively Coupled Plasma-Atomic Emission Spectrometer, ICPS-7500 (Shimadzu, Kyoto, Japan).

Statistical Analysis All results are expressed as the mean \pm S.D. for 3 to 6 experiments. The statistical analysis was conducted using Tukey's multiple statistical tests (SAS ver. 9.2).

\section{RESULTS}

Changes in Body Weight after the Zn-Containing Compounds Suspension Injections Figure 1 shows changes in body weight of the rats, after injections of suspension of ZnTCP, C8Zn and, C18Zn. After injections containing ZnTCP, $\mathrm{C} 8 \mathrm{Zn}$ and, C18Zn, body weights of the rats increased significantly as the same as that of the healthy rats, and were around $200 \%$ after 12 weeks, but no increase was observed in the rats which received corn oil (control) and $\mathrm{ZnSO}_{4}$ injections.

Effects of Zn-Related Compound Suspension Injections 


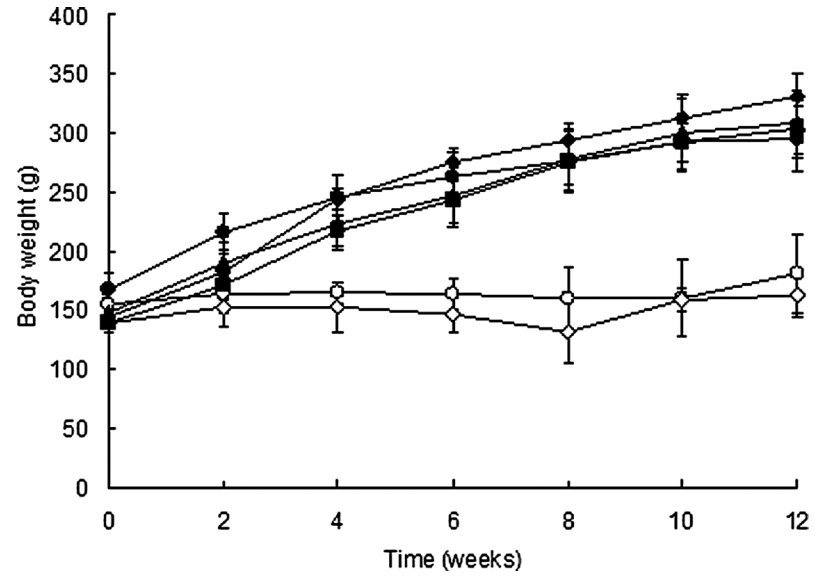

Fig. 1. Changes in Body Weight after Injections around the Alveolar Bone in Rats

The symbols represent the average and standard deviation $(n=4-6)$, respectively. Symbols: Normal rat $(\bullet)$, Control (Osteoporosis rat); $(\bigcirc), \mathrm{ZnSO}_{4}(\diamond), \mathrm{C} 8 \mathrm{Zn}(\square)$, C18Zn $(\mathbf{\Delta}), \operatorname{ZnTCP}(\bullet)$

on Plasma $\mathrm{Zn}$ and $\boldsymbol{A U C}$ of $\mathrm{Zn}$ Levels Figure 2A shows plasma $\mathrm{Zn}$ level profiles after the first injection of $\mathrm{ZnSO}_{4}$, ZnTCP, C8Zn and C18Zn suspensions. Plasma Zn levels of normal healthy group rats had almost the constant values at $1.0-1.5 \mu \mathrm{g} / \mathrm{mL}$ for over $72 \mathrm{~h}$ period, but those of diseased control had constant lower values at around $0.5 \mu \mathrm{g} / \mathrm{mL}$. In contrast, C8Zn, ZnTCP and C18 Zn-injected group had a maximum concentration, $2.68,1.49$ and $1.27 \mu \mathrm{g} / \mathrm{mL}$ at $2 \mathrm{~h}$, and after then it decreased, respectively (Table 1). The order of maximum plasma levels was $\mathrm{C} 8 \mathrm{Zn}>\mathrm{ZnTCP}>\mathrm{C} 18 \mathrm{Zn}>\mathrm{ZnSO}_{4}$. Plasma $\mathrm{Zn}$ levels of $\mathrm{ZnSO}_{4}$-injected group did not increase as the same as that of the control group.

Figure $2 \mathrm{~B}$ shows the area under the $\mathrm{Zn}$ concentration $v s$. time curve for $72 \mathrm{~h}(A U C)$ calculated using the trapezium method. The healthy rats group and C8Zn group had the highest, $A U C$ values, followed by the $\mathrm{C} 18 \mathrm{Zn}$ and ZnTCP-injected group. The $\mathrm{ZnSO}_{4}$-treated and untreated groups had very similar lower $A U C$ values.

Bone Mineral Content of Alveolar Bones Figure 3 shows the increase ratio of bone mineral content (BMC) of the alveolar bone. The BMC after the administration of corn oil (with and without OVX), $\mathrm{ZnSO}_{4}, \mathrm{C} 8 \mathrm{Zn}, \mathrm{C18Zn}$ and ZnTCP were 166.2, 75.8, 112.7, 166.9, 162.0, and 133.8, respectively. There were significant differences between the C8Zn, C18Zn and ZnTCP-administered groups with the control (OVX+corn oil) group, respectively. There was no difference between the $\mathrm{ZnSO}_{4}$-administered group and the controls.

Bone mineral content (BMC) of right femur and bone mechanical strength (BMS) of right femur as indexes of
(A)
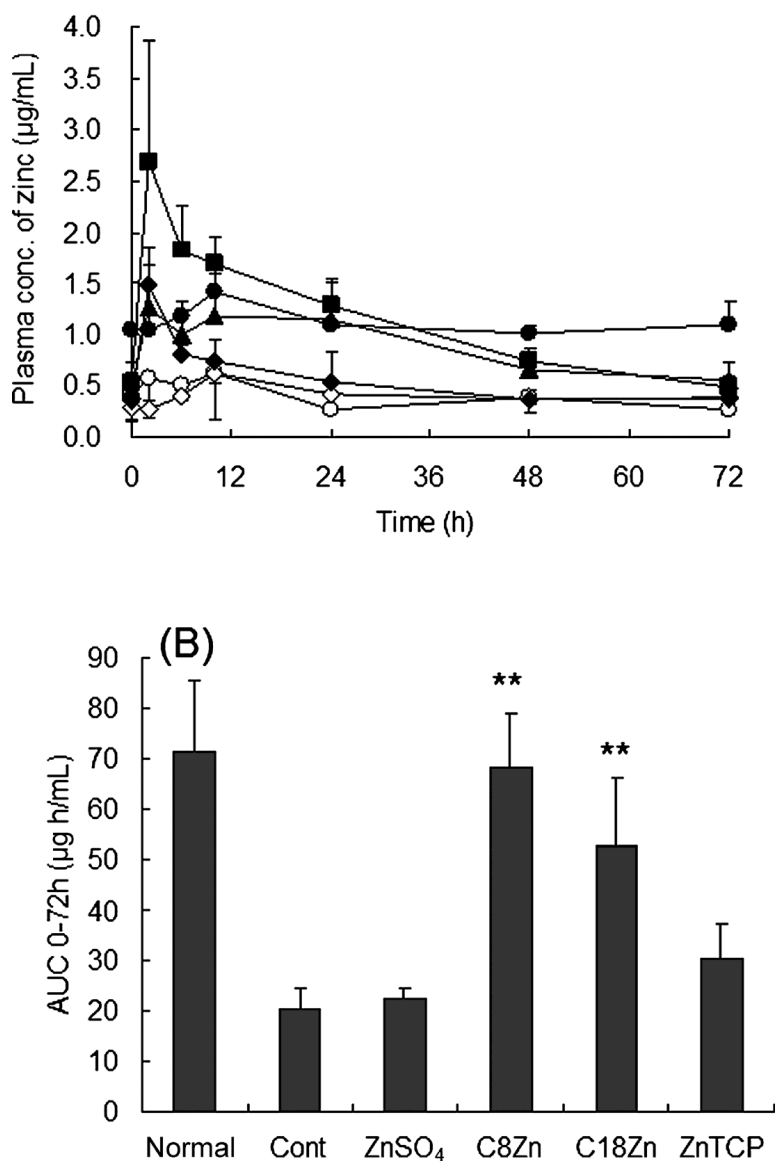

Fig. 2. Plasma $\mathrm{Zn}$ Levels (a) and $A U C$ of $\mathrm{Zn}$ (b) after Injections around the Alveolar Bone

The symbols and bars represent the average and standard deviation $(n=4-6)$, respectively. Symbols: Normal rat (๑), Control (osteoporosis rat; (O)), $\mathrm{ZnSO}_{4}$ $(\diamond), \mathrm{C} 8 \mathrm{Zn}(\mathbf{\square}), \mathrm{C} 18 \mathrm{Zn}(\mathbf{\Delta}), \mathrm{ZnTCP}(\bullet) .{ }^{* *} p<0.01$, compared to the control group (Tukey's multiple comparison tests).

therapeutic scores of osteoporosis rats.

Figure 4A shows the BMC of right femur at the experiment. BMC in the control group (OVX, corn oil) was $19.1 \mathrm{mg}$, and those in the groups administered $\mathrm{ZnSO}_{4}, \mathrm{C} 8 \mathrm{Zn}, \mathrm{C} 18 \mathrm{Zn}$ and ZnTCP were $14.8,35.8,40.8$, and $44.0 \mathrm{mg}$, respectively. There was a significant difference between the control group and the C8Zn, C18Zn and ZnTCP-administered, but not $\mathrm{ZnSO}_{4}$-adminstered group.

Figure 4B shows the effect of Zn-containing compounds injections on the BMS of the right and left femurs. BMS in the control group (OVX, corn oil) was $80.9 \mathrm{~N}$, but those in the

Table 1. Plasma Zinc Concentration $(\mu \mathrm{g} / \mathrm{mL})$ after Injections of Zinc Compounds around the Alveolar Bone

\begin{tabular}{|c|c|c|c|c|c|c|c|}
\hline & $0 \mathrm{~h}$ & $2 \mathrm{~h}$ & $6 \mathrm{~h}$ & $10 \mathrm{~h}$ & $24 \mathrm{~h}$ & $48 \mathrm{~h}$ & $72 \mathrm{~h}$ \\
\hline Normal & 1.04 & 1.04 & 1.19 & 1.41 & 1.10 & 1.01 & 1.11 \\
\hline Control & 0.43 & 0.58 & 0.50 & 0.63 & 0.27 & 0.39 & 0.27 \\
\hline $\mathrm{ZnSO}_{4}$ & 0.29 & 0.27 & 0.41 & 0.62 & 0.43 & 0.37 & 0.38 \\
\hline $\mathrm{C} 8 \mathrm{Zn}$ & 0.52 & $2.68 * *$ \#\# & $1.83^{* *}, \# \#$ & $1.68 * *$ \#\# & $1.28 * *$,\#\# & $0.74 * * \#$ & 0.49 \\
\hline C18Zn & 0.45 & 1.27 & $1.00 * \#$ & 1.19 & 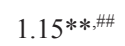 & $0.66^{*, \#}$ & 0.55 \\
\hline ZnTCP & 0.36 & 1.49 & 0.81 & 0.75 & 0.54 & 0.38 & 0.38 \\
\hline
\end{tabular}

${ }^{*} p<0.05,{ }^{* *} p<0.01$, compared to the control group, ${ }^{\#} p<0.05$, ${ }^{\#} p<0.01$, compared to the $\mathrm{ZnSO}_{4}$ (hydrophilic zinc compound) group (Tukey's multiple comparison tests). 


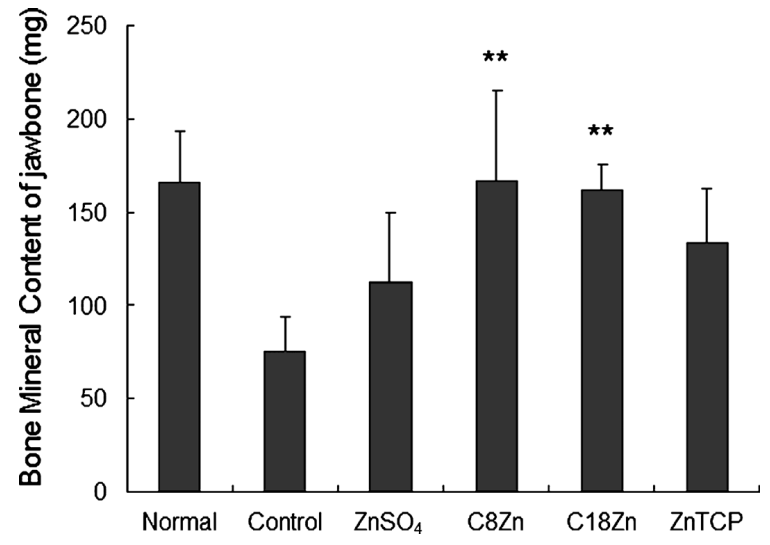

Fig. 3. Effect of Injection of Zn Related Materials on BMC of Alveolar Bone

The bars represent the average and standard deviation $(n=4-6)$, respectively ** $p<0.01$, compared to the control group (Tukey's multiple comparison tests).
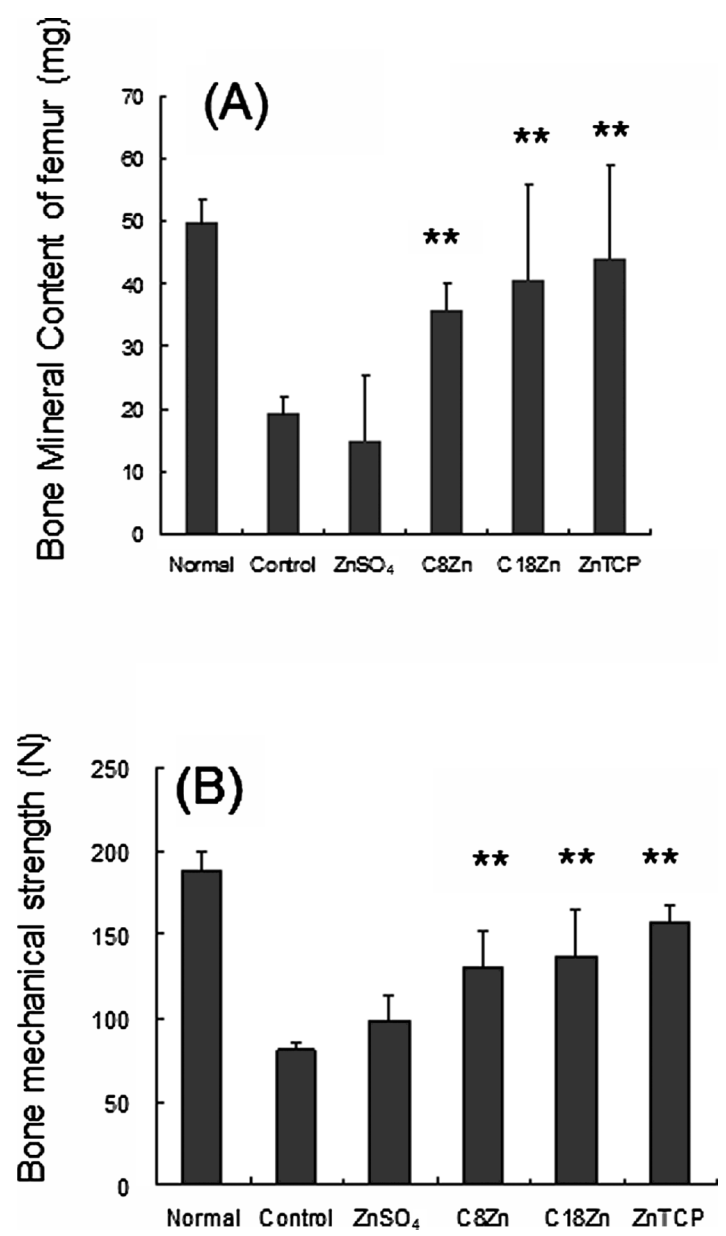

Fig. 4. Effect of Injection of Zn Related Materials on BMC (a) and BMS of Femur (b)

The bars represent the average and standard deviation $(n=4-6)$, respectively. Symbols: Normal rat $(\bullet)$, Control (osteoporosis rat; $(\bigcirc)$ ), $\mathrm{ZnSO}_{4}(\diamond), \mathrm{C} 8 \mathrm{Zn}(\mathbf{\square})$, C18Zn $(\boldsymbol{\Delta})$, ZnTCP $(\diamond)$. ** $p<0.01$, compared to the control group (Tukey's multiple comparison tests).

groups administered $\mathrm{ZnSO}_{4}, \mathrm{C} 8 \mathrm{Zn}, \mathrm{C} 18 \mathrm{Zn}$ and $\mathrm{ZnTCP}$ were $98.8,130.8,136.9$, and $157.0 \mathrm{~N}$, respectively. The ZnTCP-administered group was had a significantly higher value than the control group, but the $\mathrm{ZnSO}_{4}$-administered group did not. The
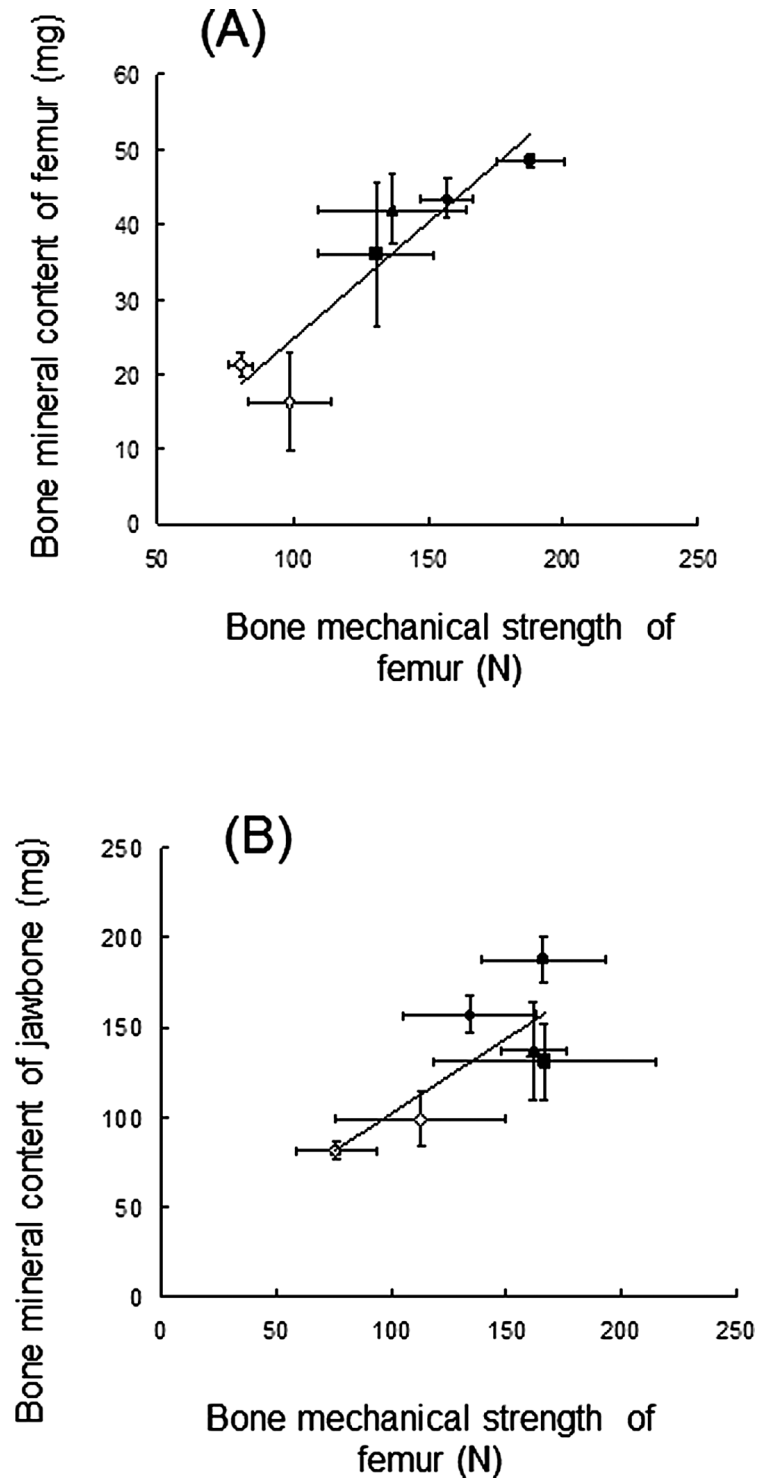

Fig. 5. Relationship between BMC and BMS of Femur (A), BMS of Femur and BMC of Alveolar Bone (B) in All Groups

The bars represent the average and standard deviation $(n=4-6)$, respectively. Symbols: Normal rat $(\bullet)$, Control (osteoporosis rat; $(\bigcirc)$ ), $\mathrm{ZnSO}_{4}(\diamond), \mathrm{C} 8 \mathrm{Zn}(\mathbf{\square})$, C18Zn $(\boldsymbol{\Delta}), \operatorname{ZnTCP}(\bullet)$

relationship between the BMS and $\mathrm{BMC}$ of the right femur (Fig. 5A) and alveolar bone (Fig. 5B) in all groups. This result indicated that increase ratio of $\mathrm{BMC}$ was increased by the injection of Zn-containing compounds in corn oil, and BMS increased with BMC. Since all the samples were injected in around alveolar bone, and the $\mathrm{BMC}$ and $\mathrm{BMS}$ of the right femur increased, the effect appears to be greater on bone closer to the injection site.

Stripped Skin Permeation of Zinc by Zinc-Containing Compounds The stripped skin permeation of $\mathrm{Zn}$ in hydrophilic ointment was shown in Fig. 6. Because the influence of the injection was higher than other compounds, the only C8Zn and ZnTCP were examined. The cumulative amount of $\mathrm{Zn}$ from its hydrophilic ointment of C8Zn and ZnTCP was 15.06 and $3.91 \%$, respectively. Stripped skin permeation of C8Zn was significant higher than that of ZnTCP $(p<0.01)$. 


\section{DISCUSSION}

Effects of Zn Related Material Suspension Injections on Plasma Zn Levels of the Zn Deficient Rat The plasma $\mathrm{Zn}$ levels of C8Zn, C18Zn and ZnTCP group rats increased after administrations of $\mathrm{Zn}$ related material suspension injections (Fig. 2A), and after $2 \mathrm{~h}$, their levels decreased with elapse of the time, respectively. In contrast, in $\mathrm{ZnSO}_{4}$ and control groups, their plasma $\mathrm{Zn}$ levels were not changed in all experimental period. In general, plasma $\mathrm{Zn}$ levels in the rats were maintained to keep at homeostatic constant values by supporting from endogenous and exogenous $\mathrm{Zn}$ resources. Plasma $\mathrm{Zn}$ levels of the normal rat group were kept at a constant value by mainly $\mathrm{Zn}$ supplying from the daily foods, but the levels of the diseased control rats were supposing from limited endogenic resource caused by dissolution of bone matrices under current animal experimental condition ( $\mathrm{Zn}$ deficiency). ${ }^{19)}$ Plasma $\mathrm{Zn}$ levels of the other group rats (C8Zn, C18Zn, $\mathrm{ZnTCP}$ and $\mathrm{ZnSO}_{4}$ ) were supported from both of external $\mathrm{Zn}$ administrations and endogenous $\mathrm{Zn}$ release (Fig. 2A).

Plasma $\mathrm{Zn}$ levels of $\mathrm{ZnSO}_{4}$ group rats did not increase after the administration, since it may be that $\mathrm{ZnSO}_{4}$ was water-soluble material, and so, those dissolved, metabolized and eliminated very fast reflecting their solubility in a body fluid, before reaching an equilibrium $\mathrm{Zn}$ concentration in plasma. In contrast, C8Zn, ZnTCP and C18Zn groups had higher plasma $\mathrm{Zn}$ profiles, those had significantly different pharmacokinetics properties in a body, since all of the materials had slower dissolution rate in a body fluid.

AUC of C8Zn, C18Zn and ZnTCP administered group (Fig. 2B) were significant increased compare with that of the control group, reflecting of their plasma Zn profiles. C8Zn, C18Zn and ZnTCP have lower solubility against to water, however, their in-vivo dissolution rate might be appropriate increasing of plasma $\mathrm{Zn}$ level in a blood circulation system. In contrast, since $\mathrm{ZnSO}_{4}$ has high water solubility, it might be too quickly eliminated after the injection. Therefore, plasma $\mathrm{Zn}$ level did not increase in plasma in a blood circulation system. So, $A U C$ of $\mathrm{ZnSO}_{4}$ administered group did not increase as compared with that of the control group.

Since plasma $\mathrm{Zn}$ level was depended on a balance of $\mathrm{Zn}$ release and elimination rates, solubility of their materials affected on their profiles. These results suggested that the $\mathrm{Zn}$ pharmacokinetics of the lipophilic zinc compounds (C8Zn and $\mathrm{C} 18 \mathrm{Zn}$ ) were remarkably different from $\mathrm{ZnSO}_{4}$ (water-soluble zinc compound) and ZnTCP (water-insolubility).

Therapeutic Effects of C8Zn and C18Zn Injections on BMC and BMS of Alveolar Bone in the $\mathrm{Zn}$ Deficient Rat Suspension injections containing hydrophilic and/or lipophilic $\mathrm{Zn}$ related compounds were administered for $\mathrm{Zn}$-deficient rats around alveolar bone at once a week for 12 weeks. After the administrations, BMC of alveolar bone (Fig. 3), BMC and BMS of femur bone (Fig. 4) were measured and evaluated as local and systemic therapeutic effects. The body weight of C8Zn, C18Zn and ZnTCP group rats (Fig. 1) increased continuously and reached the same level as that of the normal group after 12 weeks. In contrast, the body weights of $\mathrm{ZnSO}_{4}$ and the control groups were unchanged. Since $\mathrm{Zn}$ promotes protein synthesis, and the proliferation and differentiation of all types of boy cells, ${ }^{3)}$ it is well known that $\mathrm{Zn}$ induced to increasing of body weight. Current result suggested that the pharmacological effects of C8Zn and C18Zn were almost the equal to that of ZnTCP, respectively.

Next, change of BMC of alveolar bones was investigated (Fig. 3). Before injection, BMC of alveolar bone was not change in $\mathrm{Zn}$-deficient bilaterally ovariectomized rats. The systemic effects of $\mathrm{Zn}$-compounds injection were further supported by increases in the BMC and BMS (Figs. 3, 4). The BMC and BMS of the $\mathrm{ZnSO}_{4}$ administrated group were almost comparable as those of the control group. On the other hand, $\mathrm{BMC}$ and $\mathrm{BMS}$ of $\mathrm{C} 8 \mathrm{Zn}$ and $\mathrm{C} 18 \mathrm{Zn}$ for 12 weeks were significantly $(p<0.01)$ higher than those of the control group, respectively. Their increasings in BMC and BMS of femur were considered as a systemic whole body effect, since the $\mathrm{C} 8 \mathrm{Zn}$ and $\mathrm{C} 18 \mathrm{Zn}$ suspensions were injected in far local sits around nearby alveolar bones. In addition, it was revealed that relationship between BMC and BMS of femur by applications of the $\mathrm{Zn}$ related compounds (Fig. 5A). Furthermore, the BMS of femur and BMC of alveolar bone were correlated (Fig. 5B). Since it has been observed that there is a correlation between the BMS of femur and a BMC of alveolar bone, it is presumed that in alveolar bones with increasing BMC, strength also increases.

In these results, $\mathrm{ZnSO}_{4}$ administered group, all of the therapeutic scores, such as the plasma $\mathrm{Zn}$ concentration, $A U C$ of $\mathrm{Zn}, \mathrm{BMC}$ of alveolar bones, body weight and BMC and BMS of femurs are lower as the same as those of the control. It is considered that administration of $\mathrm{ZnSO}_{4}$ solution had lower therapeutic effect for improvement of bone remodeling, since the compound had fast in-vivo distribution, metabolism and elimination rate, reflecting high water solubility. In contrast, since C8Zn, C18Zn, and ZnTCP have relatively high lipid solubility, the plasma $\mathrm{Zn}$ concentration, $A U C$ of $\mathrm{Zn}$, body weight, the BMC and BMS of femurs and BMC of alveolar bone significantly increased, respectively. With all these results, applying comparatively high lipid solubility compound may lead to remain in tissues and could sustain to relief $\mathrm{Zn}$ and show high therapeutic effect. As for the pharmacologic effect on the alveolar bone promoting enhancement, lipophilic compounds of zinc (C8Zn and C18Zn) and ZnTCP are more than it in equivalence.

It is assumed that $\mathrm{Zn}$ release patterns from the dosage forms and their amount of the doses of $\mathrm{Zn}$ appear to play a role in efficacy deeply, therefore, further study will be needed.

Therapeutic Opportunity of C8Zn and C18Zn to Apply trans-Mucosal Delivery System for Improvement of BMC and BMS of Alveolar Bone in the $\mathrm{Zn}$ Deficient Rat On the other hand, considering improvement in the patient QOL, it is thought that an application by the intraoral ointment and toothpaste is better than an injection. Furthermore, when clinical use of these compounds, compounds were required consideration of membrane permeability. In this section, stratum corneum stripped rat skin was used as mimic mucosal membrane. Cutaneous permeability of stripped rat skin and porcine oral mucosal membrane permeability were similar (data not shown). As the administration of C8Zn and ZnTCP suspension injections had high therapeutically effective results on improvement of alveolar bones mineral content in the above section, the both materials were used as the test bulk materials to prepare for hydrophilic cream. The creams were tested hairless rat percutaneous absorption drug delivery. Stripped rat skin permeability of C8Zn group was shown higher than 


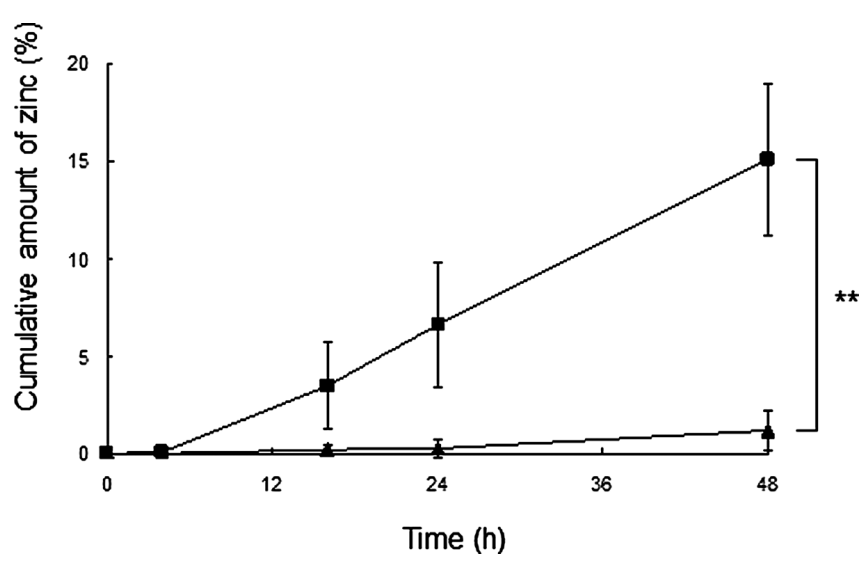

Fig. 6. Cumulative Amount of $\mathrm{Zn}$ after Hydrophilic Cream Containing Zn Related Materials Applied to Stripped Hairless Rat Skin

ZnTCP ( $\mathbf{\Delta})$, C8Zn ( $\mathbf{\square})$. The bars represent the average and standard deviation $(n=4-6)$, respectively. ${ }^{* *} p<0.01$ (Tukey's multiple comparison tests).

5-times compared with ZnTCP (Fig. 6). ZnTCP is a compound based on tricalcium phosphate, and distribution of the skin may be comparatively low compared with $\mathrm{C} 8 \mathrm{Zn}$ with high lipophilic compounds. Moreover, ZnTCP is relatively stable in neutral solution and $\mathrm{Zn}$ releases from $\mathrm{ZnTCP}$ in acidic region, the difference by release with $\mathrm{pH}$ could be affected stripped rat skin permeability.

In these results, the plasma $\mathrm{Zn}$ concentration, $A U C$ of $\mathrm{Zn}$, $\mathrm{BMC}$ of alveolar bone, BMC and BMS of femur, and cutaneous permeability. Since C8Zn had comparatively high lipid solubility, it was a compound with high utility as candidate of the bulk drug for formulation of cream preparations. In further study, we will apply the formulation containing the compound to the membrane of a model rat, and determine therapeutic effects, such as bone quantity changes.

Acknowledgements This work was supported in part by a Grant-in-Aid for Scientific Research (C) (No. 17500322), Grant-in-Aid for Young Scientists (B) (No. 19790141) and HAITEKU (2004-2008) from the Ministry of Education, Culture, Sports, Science and Technology of Japan. The author gratefully acknowledges the technical assistance of Ms. Mia Yoshida, Mr. Makoto Kaneko, Ms. Manami Takemasa and Dr. Chieko Yoshihara.

\section{REFERENCES}

1) Jeffcoat MK. Safety of oral bisphosphonates: controlled studies on alveolar bone. Int. J. Oral Maxillofac. Implants, 21, 349-353 (2006).

2) Roberts WE, Huja S, Roberts JA. Bone modeling: biomechanics, molecular mechanisms, and clinical perspectives. Semin. Orthod., 10, 123-161 (2004).

3) Czerwinski AW, Clark ML, Serafetinides EA, Perrier C, Huber W.
Safety and efficacy of zinc sulfate in geriatric patients. Clin. Pharmacol. Ther., 15, 436-441 (1974).

4) Szathmári M, Steczek K, Szücs J, Holló I. Zinc excretion in osteoporotic women. Orv. Hetil., 134, 911-914 (1993).

5) Relea P, Revilla M, Ripoll E, Arribas I, Villa LF, Rico H. Zinc, biochemical markers of nutrition, and type I osteoporosis. Age Ageing, 24, 303-307 (1995).

6) Walsh CT, Sandstead HH, Prasad AS, Newberne PM, Fraker PJ. Zinc: health effects and research priorities for the 1990s. Environ. Health Perspect., 102 (Suppl. 2), 5-46 (1994).

7) Otsuka M, Marunaka S, Matsuda Y, Ito A, Layrolle P, Naito H, Ichinose N. Calcium level-responsive in-vitro zinc release from zinc containing tricalcium phosphate (ZnTCP). J. Biomed. Mater. Res., 52, 819-824 (2000).

8) Otsuka M, Ohshita Y, Marunaka S, Matsuda Y, Ito A, Ichinose N, Otsuka K, Higuchi WI. Effect of controlled zinc release on bone mineral density from injectable $\mathrm{Zn}$-containing beta-tricalcium phosphate suspension in zinc-deficient diseased rats. J. Biomed. Mater. Res. A, 69, 552-560 (2004).

9) Kawamura H, Ito A, Miyakawa S, Layrolle P, Ojima K, Ichinose N, Tateishi T. Stimulatory effect of zinc-releasing calcium phosphate implant on bone formation in rabbit femora. J. Biomed. Mater. Res., 50, 184-190 (2000).

10) Otsuka M, Oshinbe A, Legeros RZ, Tokudome $Y$, Ito A, Otsuka K, Higuchi WI. Efficacy of the injectable calcium phosphate ceramics suspensions containing magnesium, zinc and fluoride on the bone mineral deficiency in ovariectomized rats. J. Pharm. Sci., 97, 421-432 (2008).

11) Tokudome $\mathrm{Y}$, Ito A, Otsuka M. Effect of zinc-containing $\beta$-tricalcium phosphate nano particles injection on jawbone mineral density and mechanical strength of osteoporosis model rats. Biol. Pharm. Bull., 34, 1215-1218 (2011).

12) Ito A, Otsuka M, Kawamura H, Ikeuchi M, Ohgushi H, Sogo Y, Ichinose N. Zinc-containing tricalcium phosphate and related materials for promoting bone formation. Curr. Appl. Phys., 5, 402-406 (2005).

13) Ito A, Ojima K, Naito H, Ichinose N, Tateishi T. Preparation, solubility, and cytocompatibility of zinc-releasing calcium phosphate ceramics. J. Biomed. Mater. Res., 50, 178-183 (2000).

14) Yamaguchi M, Kishi S. Prolonged administration of beta-alanyl-L-histidinato zinc prevents bone loss in ovariectomized rats. Jpn. J. Pharmacol., 63, 203-207 (1993).

15) Suda T, DeLuca HF, Tanaka Y. Biological activity of 25-hydroxyergocalciferol in rats. J. Nutr., 100, 1049-1052 (1970).

16) Makino T, Saito M, Horiguchi D, Kina K. A highly sensitive colorimetric determination of serum zinc using water-soluble pyridylazo dye. Clin. Chim. Acta, 120, 127-135 (1982).

17) Tokudome $Y$, Otsuka M, Ito A, LeGeros RZ. Long-term therapeutic effect of novel calcium phosphate-based compounds injected in ovariectomized rats. J. Biomed. Mater. Res. B Appl. Biomater., 90, 229-237 (2009).

18) Peng TC, Kusy RP, Garner SC, Hirsch PF, De Blanco MC. Influence of lactation and pregnancy+lactation on mechanical properties and mineral content of the rat femur. J. Bone Miner. Res., 2, 249-257 (1987).

19) Williams RJ. Zinc: what is its role in biology? Endeavour, 8, 65-70 (1984). 